condition from Experiment 1, is also shown. It is not strictly comparable because the $S s$ in the two experiments are from different institutions, but it is probably a good first approximation. It should be noted that only Trial 1 gives a pure measure of visual search. Subsequent trials are mixtures of search behavior and learning, although the same rank ordering of performance is evident for every trial.

\section{DISCUSSION}

It is reasonable to inquire if one single explanation can account for both main effects, step size and variability of step size. Two possibilities are suggested. They deal with (1) local field density and (2) area of the generating discs used to produce the number fields. The local density values in Table 2 bear a low positive correlation to the mean number of points connected (Table 2). The usual density explanation (Eriksen, 1955) indicates that the larger the density, the slower the search and would require a negative correlation. Hence, in a serial search task of this type, field density, within the present limits, does not give indication of being an important variable. A qualification is in order, however. The use of a unit disc to measure density is purely arbitrary. Some other radius or perhaps some other geometric form might yield a different set of relations for local density and search performance.

An alternative explanation is forthcoming if the area of the largest generating disc is considered for each of the variable conditions. In Condition IV, the largest disc has a radius of 1.5 in. as opposed to $1.0 \mathrm{in}$. in Condition 1F. The respective largest areas are 7.06 and 3.14 in. $^{2}$. A similar comparison of Conditions $2 \mathrm{~V}$ and $2 \mathrm{~F}$ shows respective largest areas of 19.62 and 12.56 in. $^{2}$. Thus, even with average step size held constant, larger areas must be scanned for variable than for fixed conditions. This suggests that for the conditions studied, the number of points connected is functionally related to the area searched through rather than the density within that area.

\section{REFERENCES}

ERIKSEN, C. Partitioning and saturation of visual displays and efficiency of visual search. Journal of Applied Psychology, 1955, 39, 73-77.

GREEN, B., \& ANDERSON, L. Color coding in a visual search task. Journal of Experimental Psychology, 1956, 51, 19-24.

UNDERWOOD, B. Distributed practice on the Tsai-Partington numbers test. Perceptual \& Motor Skills, 1961, 12, 325-326.

UNDERWOOD, B. Experimental psychology. New York: Appleton-Century-Crofts, 1966,

WEBER, R., \& CASTLEMAN, J. Metered memory search. Psychonomic Science, 1969. 16, 311-312.

WEBER, R., CROSS, M., \& CARLTON, M. Searching circular sequences. Journal of Experimental Psychology, 1968, 78, 588-592.

WILLIAMS, L. The effect of target specification on objects fixated during visual search. Perception \& Psychophysics, 1966, 1, 315-318.

\section{NOTE}

1. This study was supported in part by the Research Foundation, Oklahoma State University. The authors wish to acknowledge the help of Larry Tomlinson in preparation of stimulus materials and David Shoemaker for computer assistance.

\title{
Selection strategies and reversal-nonreversal shifts in verbal discrimination transfer
}

\begin{abstract}
JOHN W. DEICHMANN, I FRED A. MINNIGERODE III, and DONALD $H$. KAUSLER, St. Louis University, St. Louis, Mo. 63103
\end{abstract}

Verbal discrimination transfer with structured lists that permit the operation of an intrapair selection strategy was compared for reversal and nonreversal shift conditions. Reversal transfer was significantly superior to nonreversal preexperimental dimension, such as word frequency. In their transfer test, Kausler and Farzanegan employed conditions analogous to the reversal and partial reversal shift conditions indigenous to other verbal learning tasks (e.g., Kendler, Kendler, \& Sanders, 1967). Their use of a single dimension (word frequency) in constructing lists, however, precluded the inclusion of a nonreversal shift condition. By employing $W$ and $R$ items that varied systematically on two dimensions (word frequency and word length), the present study permitted a contrast between reversal and nonreversal shift strategies in VD transfer. Generalizing from other areas of research on reversal-nonreversal shifts (Kendler \& Kendler, 1962), it was hypothesized that a reversal shift strategy would be more efficacious than a nonreversal shift strategy in VD transfer.

\section{METHOD}

The 96 Ss, undergraduate students who were naive with respect to prior participation in discrimination-learning studies, were assigned alternately to the three groups $(\mathrm{N}=32)$, two experimental and one control, representing the three main conditions of the study. The Ss in each group learned two 12-pair lists conforming to a $W_{1}-R_{1}, W_{2}-R_{2}$ VD transfer paradigm (Kausler, Fulkerson, \& Eschenbrenner, 1967). That is, different sets of specific words served as $W$ and $R$ items on the two lists. However, the words on both lists were selected on the basis of two dimensions, frequency and length, each with two attributes (low and high frequency; four letters and seven letters). List 1 , for both experimental conditions (Groups RV and NRV), permitted a selection strategy in which one of the dimensions was the relevant one differentiating between Intrapair $\mathbf{W}$ and $\mathbf{R}$ items and the other dimension was irrelevant with respect to intrapair discriminations. List 2 for the reversal condition (Group RV) continued to have the same relevant dimension, but with the attributes associated with $W$ and $R$ items on List 1 now being reversed. For the nonreversal condition (Group NRV), the irrelevant dimension of List 1 became the relevant dimension of List 2 , and the relevant dimension of List 1 became irrelevant. For the control condition (Group C), List 1 did not permit the operation of a systematic selection strategy based on the word dimensions. List 2 , however, contained relevant and irrelevant dimensions in common with the two experimental conditions. Between-group variations were derived by way of List 1 . That is, all three groups received a common List 2. 
Ninety-six words were assigned to two initial pools of 48 words each. The two word pools were used to construct two sets. A and B, of Lists 1 and 2, which provided two independent replications of the study $(\mathrm{N}=16$ per group for each replication). The set effect was subsequently found to be negligible for the acquisition of both List 1 and List 2, and the two sets were combined for the analyses reported below. Each word pool contained 24 low-frequency ( 1 per million) and 24 high-frequency (AA; Thorndike \& Lorge, 1944) words, with 12 four-letter and 12 seven-letter words at each frequency value. Four different lists were prepared as List 2 (Lists $2 \mathrm{a}, \mathrm{b}, \mathrm{c}$, and d). The relevant dimension for Lists $2 a$ and $2 b$ was word frequency. Intrapair $R$ and $W$ items were low- and high-frequency words, respectively, for List $2 a$, and vice versa for List $2 b$ (half of the $R$ items were four-letter words, half were seven-letter words in each list). The relevant dimension for Lists $2 \mathrm{c}$ and $2 \mathrm{~d}$ was word length. Intrapair $R$ and $W$ items were four-letter and seven-letter words, respectively, for List $2 c$, and vice versa for List $2 d$ (half of the $R$ items were low-frequency words, half were high-frequency words in each list). The Ss in Groups RV, NRV, and C were assigned alternately to Lists $2 \mathrm{a}, \mathrm{b}, \mathrm{c}$, and $d(\mathrm{~N}=8$ in each subgroup). List 1 was constructed in accordance with the between-group condition and the specific nature of List 2 . Considering List $2 a$ as a prototype. Ss in Group RV having this list received a List $I$ that contained in trapair $R$ and $W$ items of high and low frequency, respectively. Half of the Ss in Group NRV having List $2 \mathrm{a}$ received a List 1 that contained intrapair $R$ and $W$ items of four-letter and seven-letter length, respectively; the other half received a List 1 that reversed the length relationship for $R$ and $W$ items. List 1 for Group $C$ contained six $W-R$ pairs in which the $R$ item was a low-frequency word (three four-letter words and three seven-letter words), and the $W$ item was a high-frequency word (three four-letter words, etc.); the remaining six pairs had high-frequency $R$ items and low-frequency $W$ items. Intrapajr and interpair associations between items were minimized as much as possible by making use of existing word-association norms when appropriate and the judgments of the Es.

The W-R pairs for each list were presented on $4 \times 6$ index cards. The $R$ items were located spatially on the right of the card for six pairs, and spatially on the left for six pairs. As a control for possible serial learning, three different random orders of pairs were employed across trials. The VD anticipation method was employed throughout, with a 4:4-sec exposure rate and a 4-sec intertrial interval (timed by a metronome). Prior to List 1 practice, the Ss in each group were given general instructions regarding the nature of VD learning and were also told that the list contained short and long words and unfamiliar and familiar words. List 1 acquisition was to a criterion of three consecutive perfect trials. Immediately after List 1 practice, all Ss were told that they were to learn a second list that was again composed of short and long words, etc. List 2 practice continued to a criterion of three consecutive perfect trials. The first trial for each list was a study trial; that is, S's selection of intrapair $R$ items began on Trial 2.

\section{RESULTS AND DISCUSSION List 1}

Means for trials to criterion (discounting Trial 1) were $5.18(1.38), 4.75(1.14)$, and $7.40(2.38)$ for Groups RV, NRV, and C, respectively. An analysis of variance revealed a significant between-group effect $[F(2,93)=21.93, \quad p<.0011$. An orthogonal component analysis indicated that the contrast between Group $\mathrm{C}$ and the combined strategy groups (RV and NRV) was significant $[F(1,93)=42.82, p<.001$, but not the contrast between Groups RV and NRV $[F(1,93)=1.04, p>.25]$. Means for errors made in reaching the criterion were $2.19(3.42), 1.56(2.24)$, and $7.78(7.10)$ for Groups RV, NRV, and C, respectively. A median test again revealed a significant between-group effect $\left[\chi^{2}(2)=29.25, \quad \mathrm{p}<.001\right]$. Separate median tests indicated that only the contrast between Group C and the combined strategy groups was significant $\left[\chi^{2}(1)=13.15, \mathrm{p}<.001\right]$. The overall finding of superior single-list VD acquisition of a structured list that permits a selection strategy replicates the earlier finding of Kausler \& Farzanegan (1969).

The effect of type of relevant dimension differentiating between $\mathrm{R}$ and $\mathrm{W}$ items (frequency vs length) was analyzed within the combined strategy groups (Groups RV and NRV). For frequency as the relevant variable, the means for trials and errors were 5.22 and 2.22 ; comparable means for length were 4.72 and 1.41 . The difference between means did not reach significance for either the trials score $[t(62)=1.44$, $\mathrm{p}>.10]$ or the errors score $[t(60)=1.08$, $\mathrm{p}>.10]$. In addition, learning rates did not differ between attributes identifying $\mathrm{R}$ items (e.g., low frequency vs high frequency) for either dimension $[\operatorname{ts}(30)<1]$.

\section{List 2}

The number of Ss reaching the criterion immediately after the first (study) trial was
Table 1

Summary Statistics for Errors on List 2

\begin{tabular}{|c|c|c|c|c|}
\hline \multirow{3}{*}{$\begin{array}{l}\text { Transfer } \\
\text { Paradigm }\end{array}$} & \multicolumn{4}{|c|}{ Relevant Dimension } \\
\hline & \multicolumn{2}{|c|}{ Word Frequency } & \multicolumn{2}{|c|}{ Word Length } \\
\hline & Mean & SD & Mean & $\mathrm{SD}$ \\
\hline $\begin{array}{l}\text { RV } \\
\text { NRV } \\
\text { C }\end{array}$ & $\begin{array}{l}1.06 \\
5.19 \\
1.81\end{array}$ & $\begin{array}{l}1.77 \\
5.93 \\
2.14\end{array}$ & $\begin{array}{r}.75 \\
1.50 \\
1.38 \\
\end{array}$ & $\begin{array}{l}1.88 \\
2.16 \\
3.12 \\
\end{array}$ \\
\hline
\end{tabular}

23, 9, and 17 in Groups RV, NRV, and C, respectively. Analyses of trials and errors yielded identical results, and only the results of the error analysis are reported here. Table 1 gives summary statistics for errors as related to both the transfer paradigm (RV, NRV, C) and the relevant dimension present on List 2 (frequency or length). A median test revealed a significant paradigm effect $\left[\chi^{2}(2)=12.33\right.$, $p<.01]$. Neither the dimension effect nor the Paradigm by Dimension interaction effect reached significance $\left[\chi^{2}(1)=2.67\right.$, $p>.10$ and $\chi^{2}(2)=1.72, \quad p>.10$, respectively]. Comparisons between paradigms yielded a significant difference between Groups NRV and RV $\left[\chi^{2}(1)=10.56, \quad \mathrm{p}<.01\right]$ and a trend toward a difference between Groups NRV and $\mathrm{C} \quad\left[\chi^{2}(1)=3.17, \quad p<.10\right]$. The comparison between Groups RV and $\mathrm{C}$ did not approach significance $\left[\chi^{2}(1)=0\right]$. The greater difficulty of a nonreversal shift than of a reversal shift supports the hypothesis stated earlier. The failure to demonstrate a significant facilitating effect for the reversal condition relative to the control condition most likely reflects the effect of priming a selective strategy in Group C via the study trial. The primed solution promoted such rapid acquisition in Group C that it abrogated its use as a control for evaluating positive transfer in Group RV.

\section{REFERENCES}

KAUSLER, D. H., \& FARZANEGAN, F. Word frequency and selection strategies in verbal-discrimination learning. Joumal of Verbal Learning \& Verbal Behavior, 1969, 8 196-201.

KAUSLER, D. H., FULKERSON, F. F,, \& ESCHENBRENNER, A. J., JR. Unlearning of List 1 right items in verbal-discrimination transfer. Journal of Experimental Psychology, $1967,75,379-385$.

KENDLER, H. H., \& KENDLER, T. S. Vertical and horizontal processes in problem solving. Psychological Review, 1962, 69, 1-16.

KENDLER, H. H., KENDLER, T. S., \& SANDERS, J. Reversal and partial: shifts with verbal material. Journal of Verbal Learning \& Verbal Behavior, 1967,6, 117-127.

THORNDIKE, E. L., \& LORGE, I. The teacher's word book of 30,000 words. New York: Bureau of Publications, Teachers College. Columbia University, 1944. NOTE

1. Now at Department of Guidance and Educational Psychology, Southern Jllinois University, Carbondale, Ill. 62901 . 